\title{
Sekitar Operator Dan Matriks Lax (Lax Pair) Untuk Persamaan Gelombang Air Tipe Kdv
}

\author{
Mashuri $^{1 *}$, Rina Reorita ${ }^{1}$, Agustini Tripena ${ }^{1}$ \\ ${ }^{1}$ Jurusan Matematika FMIPA, Universitas Jenderal Soedirman, Purwokerto \\ Jl. Dr. Soeparno No. 61, Purwokerto
}

*Email korespondensi: mashuri@unsoed.ac.id

\begin{abstract}
Abstrak
Operator dan Matriks Lax Pair merupakan operator dari sebuah persamaan diferensial parsial non linier yang dapat digunakan untuk merubah persamaan diferensial parsial dalam bentuk system persamaan diferensial biasa. Persamaan yang diperolehan akan memudahkan seseorang untuk mencari solusi dari persamaan diferensial tersebut. Dalam paper ini akan dibahas tentang penentuan operator Lax Pair dan Matriks Lax Pair dari sebuah sebuah persamaan gelombang air tipeKdV. Pencarian operator Lax Pair dimulai dengan menentukan bobot dari masing-masing suku menggunakan penskalaan invariant pada setiap variabel persamaan dalam persamaan KdV yang diberikan. Selanjutnya, operator Lax Pair dibentuk berdasarkan asumsi dari bobot yang dihasilkan. Dengan menggunakan definisi operator Lax Pair maka operator yang dicari dapat ditemukan. Matriks Lax Pair dari persamaan KdV dapat dicari menggunakan konversi dari operator yang dihasilkan. Dengan menggunakan definisi matrik Lax Pair, dan melalui operasi aljabar biasa dapat dihasilkan matriks Lax Pair.
\end{abstract}

Kata Kunci : Operator Lax Pair, Matriks Lax Pair, Persamaan Gelombang Air Tipe KdV.

\begin{abstract}
Operator and Matrix Lax Pair are operators of a non-linear partial differential equation that can be used to change partial differential equations in the form of systems of ordinary differential equations. The equation obtained will make it easier for someone to find a solution of the nonlinear partial differential equation. In this paper we will discuss the determination of the Lax Pair operator and the Lax Pair Matrix of a KdV type equation. We begin by determining the weights of each term using the invariant scaling on each variabel of equation in the KdV equation. Furthermore, the Lax Pair operator is formed based on the assumptions of the weight obtained. By using the Lax Pair operator definition, the h operator can be found. The Lax Pair matrix of the KdV equation can be found using conversion from the resulting operator. By using the Lax Pair matrix definition, and through ordinary algebraic operations a Lax Pair matrix can be produced. Because the Assumptions are set when the operator is specified, then the operator and the Lax Pair matrix are not unique.
\end{abstract}

Keywords: Lax Pair Operator, Lax Pair matrix, KdV-type equation

\section{Pendahuluan}

Algoritma solusi Invers scattering transform untuk masalah nilai awal pada persamaan NonLinear Schrodinger (NLS) focussing merupakan Algoritma yang sangat baik dalam mencari solusi persamaan NLS yang digunakan untuk menentukan posisi dan ketinggian gelombang ekstrim. Langkah pertama yang dilakukan dalam metoda ini adalah menentukan pasangan operator Lax dan Matriks Lax yang digunakan untuk merubah persamaan diferensial parsial nonlinier kedalam bentuk system persamaan yang merupakan persamaan diferensial biasa. Pasangan operator Lax (operator Lax Pair) dan Matriks Lax Pair ini menjadi kunci untuk menentukan apakah solusi persamaan diferensial nonlinier benar atau tidak (lihat [1], [2], [3],[4],[5],[6]).

Dalam paper ini akan dijelaskan penentuan operator Lax Pair dan Matriks Lax Pair untuk sebuah persamaan diferensial parsial nonlinier. Selanjutnya akan djelaskan tentang bagaimana melakukan konversi sebuah operator Lax Pair kedalam sebuah matriks Lax pair menggunakan hubungan-hubungan antara formula dan menunjukkan metoda yang sama untuk melakukan konversi kembali dari matriks ke operator. Sebagai persamaan diferensial parsial nonlinier yang dikaji di dalam paper ini adalah persamaan bertipe $\mathrm{KdV}$ [7]. Mengingat persamaan ini merupakan sebuah persamaan gelombang yang sederhana akan tetapi dapat mewakili sifat-sifat kenonlinieran air.

Secara khusus paper ini diorganisasikan sebagai berikut. Setelah pendahuluan akan dijelaskan tentang model matematika persamaan gelombang bertipe KdV. Selanjutnya akan dijelaskan tentang pegertian operator Lax Pair, 
metoda pembobotan untuk Lak Pair serta menggunakan metoda pembobotan tersebut untuk menentukan Lax Pair dari persamaan KdV. Pada bagian akhir dilakukan konversi operator Lak Pair kedalam bentuk matriks Lax Pair.

\section{Model Matematika}

Model matematika yang digunakan dalam paper ini adalah persamaan gelombang KdV yang diberikan sebagai berikut.

$$
\Delta=u_{t}+\alpha u u_{x}+u_{x x x}=0
$$

Dengan $u(x, t)$ menyatakan elevasi gelombang air, $\alpha$ adalah koefisien nonlinier dari persamaan KdV sebagai mana dapat dilihat dalam [6].

\section{Pengertian Operator Lax Pair}

Definisi1. Operator L dan M dikatakan operator Lax Pair dari sebuah persamaan diferensial nonlinear $\Delta=0$, Jika memenuhi

$$
L \psi=\lambda \psi
$$

Dengan $\lambda$ merupakan nilai eigen dari operator $\mathrm{L}$, dan

$$
\psi_{t}=M \psi
$$

$L$ dan $M$ merupakan operator diferensial linier. $\psi$ merupakan fungsi eigen dari L. Pasangan (L,M) disebut Lax Pair dari persamaan diferensial parsial (1). Persamaan (2) dan (3) bersesuaian dengan solusi dari persamaan (1). Persamaan (2) disebut juga persamaan Scrhrodinger untuk $\psi$, sementara persamaan (3) membangun pergerakan waktu dari $\psi$ (lihat [2]). Jika diasumsikan permasalahannya isospectra yaitu nilai eigen tidak berubah dalam waktu atau $\lambda_{t}=0$, maka persamaan Lax yang dipenuhi oleh $\mathrm{L}$ dan $\mathrm{M}$ dapat diturunkan sebagai berikut:

Turunan persamaan (2) terhadap $t$ memberikan

Subtitusikan (2) ke dalam (4) menghasilkan

$$
L_{t} \psi+L \psi_{t}=\lambda \psi_{t}
$$

Subtitusi (2) kedalam (5) menghasilkan

$$
L_{t} \psi+L M \psi=\lambda M \psi=M \lambda \psi
$$

$$
\begin{aligned}
& L_{t} \psi+L M \psi=M L \psi \\
& L_{t} \psi+L M \psi-M L \psi=0 \\
& \left(L_{t}+L M-M L\right) \psi=0 \\
& \left(L_{t}+[L, M]\right) \psi=0
\end{aligned}
$$

Karena (6) berlaku untuk setiap $\psi$ maka

$$
\left(L_{t}+[L, M]\right)=0
$$

Dengan 0 adalah operator nol (zero). Persamaan (7) disebut persamaan Lax dan hanya menghasilkan 0 ketika $\Delta=0$. Jika $\Delta \neq 0$ maka dibanyak kasus $\left(L_{t}+[L, M]\right)=c \Delta I$ dimana $c$ konstanta, I operator Identitas. $L$ dan $\mathrm{M}$ merupakan operator diferensial non komutatif sehingga diperlukan kehati-hatian dalam menghitung persamaan Lax. Karena

$(L \psi)_{t}=L_{t} \psi+L \psi_{t}$

$L_{t} \psi=(L \psi)_{t}-L \psi_{t}$

Dengan komutator

$[L, M]=L M-M L$

Selanjutnya akan di bahas bagaimana menentukan pasangan operator Lax untuk sebuah persamaan diferensial parsial. Perlu diingat bahwa pasangan operator Lax merupakan pasangan yang tidak tunggal. Seseorang dapat membuat pasangan operator Lax dengan ketentuan seperti yang telah dijelaskan di atas (lihat [8],[9]).

\section{Metoda Pembobotan Untuk operator Lax Pair}

Metoda pembobotan dapat digunakan untuk mencari pasangan Operator Lax, yakni dengan menentukan bobot dari masing-masing suku dalam pasangan operator Lax. Bobot diperoleh dengan melakukan penskalaan invariant untuk masing-masing suku dalam persamaan diferensial yang diberikan. Berikut ini diberikan contoh bagaimana menentukan pasangan operator Lax untuk sebuah persamaan bertipe KdV (1). 


\subsection{Pembobotan suku pada persamaan KdV}

Persamaan (1) akan simetri jika skala invariant diberikan sebagai berikut :

$$
(x, t, u) \rightarrow\left(\kappa^{a} x, \kappa^{b} t, \kappa^{c} u\right)=(\tilde{x}, \tilde{t}, \tilde{u})
$$

Dimana $\kappa$ parameter skala. Penskalaan di atas akan uniform dengan menentukan bilangan bulat a, b, c. Dengan penskalaan tersebut suku demi suku dari persamaan (1) menghasilkan $u=\kappa^{-c} \tilde{u}$ dengan turunan terhadap $\mathrm{t}$ diperoleh,

$$
\begin{aligned}
u_{t} & =\kappa^{-c} \frac{\partial \tilde{u}}{\partial \tilde{t}} \frac{\partial \tilde{t}}{\partial t}=\kappa^{-c} \frac{\partial \tilde{u}}{\partial \tilde{t}} \kappa^{b}=\kappa^{b-c} \frac{\partial \tilde{u}}{\partial \tilde{t}}=\kappa^{b-c} \tilde{u}_{\tilde{t}} \\
\alpha u u_{x} & =\alpha \kappa^{-c} \tilde{u} \kappa^{-c} \frac{\partial \tilde{u}}{\partial \tilde{x}} \frac{\partial \tilde{x}}{\partial x}=\alpha \kappa^{-2 c} \tilde{u} \frac{\partial \tilde{u}}{\partial \tilde{x}} \kappa^{a}=\alpha \kappa^{a-2 c} \tilde{u} \tilde{u}_{\tilde{x}} \\
u_{x x x} & =\frac{\partial^{2}}{\partial x^{2}}\left(\kappa^{-c} \frac{\partial \tilde{u}}{\partial \tilde{x}} \frac{\partial \tilde{x}}{\partial x}\right)=\frac{\partial^{2}}{\partial x^{2}}\left(\kappa^{-c} \frac{\partial \tilde{u}}{\partial \tilde{x}} \kappa^{a}\right)=\frac{\partial^{2}}{\partial x^{2}}\left(\kappa^{a-c} \frac{\partial \tilde{u}}{\partial \tilde{x}}\right)=\frac{\partial^{2}}{\partial x^{2}}\left(\kappa^{a-c} \tilde{u}_{\tilde{x}}\right) \\
& =\frac{\partial}{\partial x}\left(\kappa^{2 a-c} \tilde{u}_{\tilde{x} \tilde{x}}\right)=\kappa^{3 a-c} \tilde{u}_{\tilde{x} \tilde{x}}
\end{aligned}
$$

Jadi persamaan (1) dalam bentuk skala invariannya adalah

$$
\kappa^{b-c} \tilde{u}_{\tilde{t}}+\alpha \kappa^{a-2 c} \tilde{u} \tilde{u}_{\tilde{x}}+\kappa^{3 a-c} \tilde{u}_{\tilde{x} \tilde{x} \tilde{x}}=0
$$

Supaya persamaan (1) dan (12) simetri maka dapat dipilih

$$
b-c=a-2 c=3 a-c .
$$

Tanpa menghilangkan keumuman, kita dapat memilih $a=-1$, sehingga $c=2$ dan $b=-3$. Bobot $W$ dari masing-masing variabel merupakan pangkat eksponensial dari $\kappa$ dalam persamaan (7), sehingga diperoleh $W(x)=a=-1, W(t)=b=-3$ dan $W(u)=c=2$

Sementara bobot suku yang lain dapat diperoleh sebagai berikut:

$$
\frac{\partial}{\partial x}=\frac{\partial}{\partial \tilde{x}} \frac{\partial \tilde{x}}{\partial x}=\kappa^{a} \frac{\partial}{\partial \tilde{x}}
$$

Jadi

$$
\frac{\partial}{\partial \tilde{x}}=\kappa^{-a} \frac{\partial}{\partial x}
$$

Karena $a=-1$ maka

$$
\frac{\partial}{\partial \tilde{x}}=\kappa^{1} \frac{\partial}{\partial x}
$$

hal ini berarti bobot $W\left(\frac{\partial}{\partial x}\right)=1$.

Dengan cara yang sama diperoleh

Jadi

$$
\frac{\partial}{\partial t}=\frac{\partial}{\partial \tilde{t}} \frac{\partial \tilde{t}}{\partial t}=\kappa^{b} \frac{\partial}{\partial \tilde{t}}
$$

$$
\frac{\partial}{\partial \tilde{t}}=\kappa^{-b} \frac{\partial}{\partial t}
$$

karena $b=-3$ maka

$$
\frac{\partial}{\partial \tilde{x}}=\kappa^{3} \frac{\partial}{\partial x}
$$

hal ini berarti bobot $W\left(\frac{\partial}{\partial t}\right)=3$. Untuk operator $\frac{\partial^{2}}{\partial x^{2}}$ diperoleh 


$$
\frac{\partial^{2}}{\partial x^{2}}=\frac{\partial}{\partial x}\left(\frac{\partial}{\partial \tilde{x}} \frac{\partial \tilde{x}}{\partial x}\right)=\kappa^{a} \frac{\partial\left(\frac{\partial}{\partial \tilde{x}}\right)}{\partial \tilde{x}}\left(\frac{\partial \tilde{x}}{\partial x}\right)=\kappa^{a} \frac{\partial\left(\frac{\partial}{\partial \tilde{x}}\right)}{\partial \tilde{x}} \kappa^{a}=\kappa^{2 a} \frac{\partial^{2}}{\partial \tilde{x}^{2}}
$$

Jadi

$$
\frac{\partial^{2}}{\partial \tilde{x}^{2}}=\kappa^{-2 a} \frac{\partial}{\partial x}
$$

karena $a=-1$ maka

$$
\frac{\partial}{\partial \tilde{x}}=\kappa^{2} \frac{\partial}{\partial x}
$$

Hal ini berarti bobot $W\left(\frac{\partial^{2}}{\partial x^{2}}\right)=2$, demikian pula dengan cara yang sama diperoleh $W\left(\frac{\partial^{3}}{\partial x^{3}}\right)=3$. Bobot tiap suku ini akan digunakan untuk menentukan operator Lax pair dari persamaan KdV (1).

\subsection{Penentuan Operator Lax Pair}

Pada bagian sebelumnya telah dijelaskan tentang bobot masing-masing suku yang ada dalam persamaan (1). Pada bagian ini bobot tersebut akan digunakan dalam membentuk operator Lax pair persamaan (1). Berdasarkan bobot yang diperoleh kita dapat mengasumsikan suku-suku dalam operator L mempunyai bobot 2 dan dalam operator M mempunyai bobot 3, sehingga $\mathrm{L}$ dan $\mathrm{M}$ dapat dipilih sebagai berikut :

$$
\begin{gathered}
L=D_{x}^{2}+c_{1} u I \\
M=c_{2} D_{x}^{3}+c_{3} u D_{x}+\left(a(t)+c_{4} u_{x}\right) I
\end{gathered}
$$

Selanjutnya akan dicari koefisien $c_{1}, c_{2}, c_{3}, c_{4}$ untuk persamaan (23) di atas.

Turunan $L$ terhadap $t$ menghasilkan

$$
L_{t}=c_{1} u_{t} I
$$

$L M$ diperoleh sebagai berikut:

$$
\begin{aligned}
L M= & \left(D_{x}^{2}+c_{1} u I\right)\left(c_{2} D_{x}^{3}+c_{3} u D_{x}+\left(a(t)+c_{4} u_{x}\right) I\right) \\
= & c_{2} D_{x}^{5}+\left(c_{1} c_{2}+c_{3}\right) u D_{x}^{3}+\left(c_{4}+2 c_{3}\right) u_{x} D_{x}^{2}+a(t) D_{x}^{2}+\left(c_{3}+2 c_{4}\right) u_{x x} D_{x} \\
& +c_{1} c_{3} u^{2} D_{x}+c_{4} u_{x x x} I+c_{1} c_{4} u u_{x} I+c_{1} u a(t) I \\
M L= & \left(c_{2} D_{x}^{3}+c_{3} u D_{x}+\left(a(t)+c_{4} u_{x}\right) I\right)\left(D_{x}^{2}+c_{1} u I\right) \\
= & c_{2} D_{x}^{5}+\left(c_{1} c_{2}+c_{3}\right) u D_{x}^{3}+\left(3 c_{1} c_{2}+c_{4}\right) u_{x} D_{x}^{2}+a(t) D_{x}^{2}+3 c_{1} c_{2} u_{x x} D_{x} \\
& +c_{1} c_{3} u^{2} D_{x}+c_{1} c_{2} u_{x x x} I+\left(c_{1} c_{3}+c_{1} c_{4}\right) u u_{x} I+c_{1} u a(t) I
\end{aligned}
$$

Sehingga

$$
\begin{aligned}
L_{t}+[L, M]= & L_{t}+L M-M L \\
= & c_{1}\left(-u_{x x x} I-\alpha u u_{x} I\right)+\left(2 c_{3}-3 c_{1} c_{2}\right) u_{x} D_{x}^{2}+\left(c_{3}+2 c_{4}-3 c_{1} c_{2}\right) u_{x x} D_{x} \\
& +\left(c_{4}-c_{1} c_{2}\right) u_{x x x} I-c_{1} c_{3} u u_{x} I \\
= & \left(2 c_{3}-3 c_{1} c_{2}\right) u_{x} D_{x}^{2}+\left(c_{3}+2 c_{4}-3 c_{1} c_{2}\right) u_{x x} D_{x}+\left(-c_{1}+c_{4}-c_{1} c_{2}\right) u_{x x x} I \\
& -\left(c_{1} \alpha+c_{1} c_{3}\right) u u_{x} I
\end{aligned}
$$

Karena $L_{t}+[L, M]=0$, maka

$$
\begin{gathered}
2 \mathrm{c}_{3}-3 c_{1} c_{2}=0 \\
c_{3}+2 c_{4}-3 c_{1} c_{2}=0
\end{gathered}
$$




$$
\begin{aligned}
& -c_{1}+c_{4}-c_{1} c_{2}=0 \\
& c_{1} \alpha+c_{1} c_{3}=0
\end{aligned}
$$

Dengan menggunakan operasi aljabar biasa pada persamaan (26) - (29) diperoleh

$$
c_{3}=-\alpha,
$$

Dari persamaan (26) dan (27) diperoleh,

$$
\begin{aligned}
& c_{3}-2 c_{4}=0 \\
& c_{4}=\frac{1}{2} c_{3}=-\frac{1}{2} \alpha
\end{aligned}
$$

Dari persamaan (27) dan (28) diperoleh,

$$
\begin{array}{r}
c_{3}+2 c_{4}-3 c_{1} c_{2}=0 \\
-3 c_{1}+3 c_{4}-3 c_{1} c_{2}=0
\end{array}
$$

Atau

$$
c_{1}=\frac{1}{3}\left(-c_{3}+c_{4}\right)=\frac{1}{3}\left(-2 c_{4}+c_{4}\right)=-\frac{1}{3}\left(c_{4}\right)=\frac{1}{6} \alpha .
$$

Dari persamaan (28) diperoleh,

$$
-c_{1}+c_{4}-c_{1} c_{2}=-\frac{1}{6} \alpha-\frac{1}{2} \alpha-\frac{1}{6} \alpha c_{2}=0
$$

$$
c_{2}=4
$$

Jadi, Operator Lax Pair untuk persamaan KdV (1) adalah

$$
\begin{aligned}
& L=D_{x}^{2}+\frac{1}{6} \alpha u I \\
& M=-4 D_{x}^{3}-\alpha u D_{x}+\left(a(t)-\frac{1}{2} \alpha u_{x}\right) I
\end{aligned}
$$

Persamaan (34) dan (35) merupakan pasangan operator Lax yang memenuhi

$$
L \psi=\psi_{x x}+\frac{1}{6} \alpha u \psi=\lambda \psi \quad \text { dan } \quad \psi_{t}=M \psi=-4 \psi_{x x x}-\alpha u \psi_{x}+\left(a(t)-\frac{1}{2} \alpha u_{x}\right) \psi
$$

\subsection{Konversi Operator Lax Pair ke dalam Matrix Lax Pair}

Pada bagian ini akan dicari matriks Lax Pair yang memenuhi sebuah persamaan diferensial berdasarkan operator Lax Pair yang telah diperoleh. Matriks Lax Pair merupakan pasangan matriks dari sebuah persamaan diferensial yang memenuhi definisi berikut.

Definisi 2 : Diberikan dua buah matriks X dan T yang terkait dengan operator Lax pair L dan M sehingga berlaku

$$
\psi_{x}=X \psi
$$

Dan

$$
\psi_{t}=T \psi
$$

Dimana $\psi$ merupakan vektor dengan Komponen $\psi$ ditentukan oleh ordo L. Masing-masing X dan T bergantung nilai eigen $\lambda$. Jika $L$ orde 2 maka $\psi$ mengandung dua komponen

$$
\psi=\left(\begin{array}{l}
\gamma \\
\varphi
\end{array}\right)
$$

Dalam hal ini X dan T adalah matriks yang berukuran 2 x 2. Berdasarkan persamaan (37) dan (38) diperoleh:

$$
\begin{aligned}
& \psi_{x t}=X_{t} \psi+X \psi_{t} \\
& \psi_{t x}=T_{x} \psi+T \psi_{x}
\end{aligned}
$$

Oleh karena itu,

$$
X_{t} \psi+X \psi_{t}=T_{x} \psi+T \psi_{x}
$$




$$
\begin{aligned}
& X_{t} \psi-T_{x} \psi+X \psi_{t}-T \psi_{x}=0 \\
& \left(X_{t}-T_{x}\right) \psi+X T \psi-T X \psi=0 \\
& \left(X_{t}-T_{x}+[X, T]\right) \psi=0
\end{aligned}
$$

Dengan $[X, T]=X T-T X$ merupakan komutator dari matriks X dan T. Karena dalam persamaan (43) berlaku untuk sembarang $\psi$, maka

$$
X_{t}-T_{x}+[X, T]=0
$$

Persamaan (44) ini merupakan persamaan Matriks Lax atau persamaan kurvatur nol (zero-curvatur). Persamaan (48) dapat digunakan untuk menguji apakah pasangan matriks X dan T merupakan matriks Lax Pair untuk $\Delta=0$ , yakni persamaan kurvatur nol (44) dipenuhi jika dan hanya jika $\Delta=0$.

Dimulai dari persamaan (34) dan (35) yang berkaitan dengan operator L dan M, akan dikonversikan operator ini ke dalam system linier menggunakan matriks X dan T. Dengan cara yang sama seperti matriks dari system persamaan diferensial biasa, dimana satu skalar menggantikan persamaan scalar orde $\mathrm{n}$ menjadi sebuah system npersamaan orde pertama. Misalkan

$$
\varphi=\psi_{x}
$$

Jika L merupakan persamaan Orde n, maka kita harus mengenalkan persamaan (n-1) variabel baru. Definisikan vector $\Psi$ sebagai vektor untuk persamaan (37) dan (38). Seandainya L berorde 2, kita dapat menuliskan persamaan (37) dan (38) sebagai persamaan Linier yang memenuhi

$$
\left(\begin{array}{l}
\psi_{x} \\
\varphi_{x}
\end{array}\right)=\left(\begin{array}{ll}
A & B \\
C & D
\end{array}\right)\left(\begin{array}{l}
\psi \\
\varphi
\end{array}\right)
$$

Dan

$$
\left(\begin{array}{l}
\psi_{t} \\
\varphi_{t}
\end{array}\right)=\left(\begin{array}{ll}
E & F \\
G & H
\end{array}\right)\left(\begin{array}{l}
\psi \\
\varphi
\end{array}\right)
$$

Dengan elemen-elemen A sampai H tak diketahui. Berdasarkan persamaan (36) diperoleh

$$
\varphi_{x}=\psi_{x x}=\left(\lambda-\frac{1}{6} \alpha u\right) \psi
$$

Dalam bentuk matriks persamaan (48) dapat ditulis menjadi

$$
\left(\begin{array}{l}
\psi_{x} \\
\varphi_{x}
\end{array}\right)=\left(\begin{array}{cc}
0 & 1 \\
\lambda-\frac{1}{6} \alpha u & 0
\end{array}\right)\left(\begin{array}{l}
\psi \\
\varphi
\end{array}\right)
$$

Dari persamaan (49) diperoleh

$$
X=\left(\begin{array}{cc}
0 & 1 \\
\lambda-\frac{1}{6} \alpha u & 0
\end{array}\right)
$$

Sementara itu untuk mendapatkan E dan H, dari persamaan (48) diperoleh

$$
\begin{aligned}
& \varphi_{x}=\lambda \psi-\frac{1}{6} \alpha u \psi \\
& \varphi_{x x}=\lambda \varphi-\frac{1}{6} \alpha u \varphi--\frac{1}{6} \alpha u_{x} \psi
\end{aligned}
$$

Dengan mensubstitusikan persamaan (51) kedalam (36), diperoleh

$$
\begin{aligned}
& \psi_{t}=-4 \varphi_{x x}-\alpha u \varphi+\left(a(t)-\frac{1}{2} \alpha u_{x}\right) \psi \\
& =-4\left(\lambda \varphi-\frac{1}{6} \alpha u \varphi--\frac{1}{6} \alpha u_{x} \psi\right)-\alpha u \varphi+\left(a(t)-\frac{1}{2} \alpha u_{x}\right) \psi \\
& =\left(a(t)+\frac{1}{6} \alpha u_{x}\right) \psi-\left(4 \lambda+\frac{1}{3} \alpha u\right) \varphi
\end{aligned}
$$


Hal yang sama berlaku,

$$
\varphi_{t}=\psi_{x t}=\left(-4 \lambda+\frac{1}{3} \alpha \lambda u-\frac{1}{18} \alpha^{2} u^{2}+\frac{1}{6} \alpha u_{x x}\right) \psi+\left(a(t)-\frac{1}{6} \alpha u_{x}\right) \varphi
$$

Sehingga bentuk matriks dari kedua persamaan di atas adalah

$$
\begin{aligned}
& \left(\begin{array}{l}
\psi_{t} \\
\varphi_{t}
\end{array}\right)=\left(\begin{array}{cc}
a(t)+\frac{1}{6} \alpha u_{x} & -\left(4 \lambda+\frac{1}{3} \alpha u\right) \\
-4 \lambda+\frac{1}{3} \alpha \lambda u-\frac{1}{18} \alpha^{2} u^{2}+\frac{1}{6} \alpha u_{x x} & a(t)-\frac{1}{6} \alpha u_{x}
\end{array}\right)\left(\begin{array}{l}
\psi \\
\varphi
\end{array}\right) \\
& T=\left(\begin{array}{cc}
a(t)+\frac{1}{6} \alpha u_{x} & -\left(4 \lambda+\frac{1}{3} \alpha u\right) \\
-4 \lambda+\frac{1}{3} \alpha \lambda u-\frac{1}{18} \alpha^{2} u^{2}+\frac{1}{6} \alpha u_{x x} & a(t)-\frac{1}{6} \alpha u_{x}
\end{array}\right)
\end{aligned}
$$

Matrik X dan T yang dihasilkan dalam persamaan (50) dan (54) merupakan Matriks Lax Pair yang memenuhi (37) dan (38).

\section{Kesimpulan}

Dalam paper ini telah dibahas tentang bagaimana operator lax dan matrikx lax pair dapat dicari dengan melakukan pembobotan melalui transfomasi invariant setiap variabelnya. Dengan menggunakan metoda tersebut diperoleh operator Lax pair untuk persamaan KdV. Sementara Matriks Lax Pair nya dapat diperoleh dengan mengkonversi operator lax yang telah diperoleh terlebih dahulu kedalam definisi dari matriks lax pair.

\section{Ucapan Terima Kasih}

Penulis mengucapkan terimakasih kepada kementrian Riset DIKTI yang telah mendanai penelitian ini dengan no kontrak penelitian 068/SP2H/LT/DRPM/IV/2017.

\section{Daftar Pustaka:}

[1] M. J. Ablowitz and H. Segur. The inverse scattering transform on the infinite integral. In Solitons and the Inverse Scattering Transform, volume 4 of Studies in Applied Mathematics, chapter 1, pages 1-91. Society for Industrial and Applied Mathematics (SIAM), Philadelphia, 1981.

[2] M.J. Ablowitz and H. Segur. Solitons and the Inverse Scattering Transform. SIAM studies in applied mathematics. Society for Industrial and Applied Mathematics, 1981.

[3] V. E. Zakharov and A. B. Shabat. Exact theory of two-dimensional selffocusing and one-dimensional selfmodulation of waves in nonlinear media. Sov. Phys.JETP, 34:62-69, 1972.

[4] Graham W Griffiths, LaxPair, City University, UK, 2012.

[5] T.I Habibullin, A. R. Khakimova, M. N. Poptsova, On a method for constructing the Lax pairs for nonlinear integrable equations, J. Phys. A: Math. Theor. 49, 035202 (35pp),UK,2016.

[6] T. Aktosun. Inverse scattering transform and the theory of solitons. In Robert A. Meyers, editor, Encyclopedia of Complexity and Systems Science, pages 4960- 4971. Springer New York, 2009.

[7] Laely Kurniasih , Mashuri, Rina Reorita, Penyelesaian Persamaan Kadomtsev Petviashvili Menggunakan Metode Asimtotik, Jurnal Matematika Integratif, Volume 13 No 1, , pp 20-27, Indonesia, 2017.

[8] P. D. Lax. Integrals of nonlinear equations of evolution and solitary waves. Comm. Pure Appl. Math., 21(5):467-490, 1968.

[9] W. Hereman. A list of nonlinear PDEs and DDEs with their Lax pairs in operator and matrix form. Private Communication, 2011. 